\title{
Atravessar as fronteiras da modernidade: movimentos de transversalidade no contexto europeu e brasileiro
}

\author{
Aline Leal Fernandes Barbosa* *
}

\begin{abstract}
Resumo
Se os paradigmas estéticos da modernidade buscavam acentuar a autonomia da arte, sua radical separação de qualquer interesse exterior à própria obra, a distância entre expressões culturais altas e baixas, assistimos contemporaneamente à crescente aproximação entre as esferas culturais, apostando no intercâmbio horizontal em detrimento da verticalização polarizada e sinalizando a necessidade de novos recortes que permitam dar conta da tenuidade das fronteiras entre a chamada alta cultura e a cultura midiática de mercado.

Palavras-chave: Modernismo. Bens simbólicos. Autonomia. Demarcação.
\end{abstract}

\section{Crossing the Frontiers of Modernity: Transversality Movements in The European and Brazilian Context}

\begin{abstract}
If the aesthetic paradigms of modernity sought to accentuate the autonomy of art, its radical separation from any interest outside the work itself, and the distance between high and low cultural expressions, nowadays we are witnessing the increasing approximation between cultural spheres, betting on horizontal exchange to the detriment of polarized verticalization and signaling the need for new cuts that allow to realize the tenuity of the boundaries between the so-called high culture and the media culture of the market.
\end{abstract}

Keywords: Modernism. Symbolic market goods. Autonomy. Demarcation.

* Pontifícia Universidade Católica do Rio de Janeiro (PUC - Rio). Doutora e mestra pelo programa de Literatura, Cultura e Contemporaneidade da PUC-Rio. Graduada em jornalismo (2006) pela mesma instituição. 
Kafka é bom porque não escrevia para ser lido. Mas por outro lado Shakespeare é bom porque escrevia de olho no shilling que cobrava de cada espectador.

(Gustavo Flávio em Bufo Spallanzani, Rubem Fonseca)

Personagens ficcionais paradigmáticas são frequentemente evocadas por críticos para conduzir sua análise, uma vez que possibilitam lançar um olhar transversal às obras, além de emprestar o brilho da ficção literária. Destas personagens, provavelmente as flaubertianas ocupam lugar proeminente, sobretudo, e muito a propósito, quando se quer abordar o modernismo. Podemos antecipar que dois importantes interlocutores deste artigo - Pierre Bourdieu e Andreas Huyssen, em As regras da arte e Memórias do modernismo, respectivamente - foram também buscar em Flaubert o ponto de partida de suas análises. Aqui, como Bourdieu, começamos com Arnoux e Fréderic, de A educação sentimental: personagens duplas que caminham sobre uma linha fronteiriça, ou sobre uma corda bamba, correndo o risco de pisar em falso e tropeçar entre os campos, quiçá desabar sobre o abismo.

Arnoux é comerciante de quadros e proprietário do jornal "A Arte Industrial", instância de consagração que explora economicamente o trabalho dos artistas. Representante do dinheiro e dos negócios no seio do universo da arte, está "destinado a aparecer como um burguês para os artistas e um artista para os burgueses" (BOURDIEU, 1996, p. 28). Fréderic, por sua vez, também incorpora essa figura dupla: oscila entre o universo burguês e o intelectual-artístico, alimentando veleidades ao mesmo tempo artísticas, literárias e mundanas, além de hesitar entre o amor puro, que dedica à Sra. Arnoux, e o amor mercenário pela Sra. Dambreuse. Situado entre os dois mundos, está o salão de Rosanette, a cortesã - um mundo intermediário, e um tanto suspeito, dominado por “"mulheres livres', portanto capazes de cumprir até o fim a função de mediadoras entre os 'burgueses', dominantes tout court, e os artistas, dominantes-dominados" (BOURDIEU, 1996, p. 22). Impossível escapar aqui à associação da prostituta como figura simbólica da relação do artista com o mercado. De acordo com Bourdieu: "Baudelaire ou Flaubert interrogam-se, no mesmo momento, sobre a relação entre sua função e a da prostituta" (BOURDIEU, 1996, p 22).

Seres indeterminados, ou determinados à indeterminação, embaralham as demarcações dos campos devido à coexistência em universos que deveriam estar separados. São, portanto, destinados à ruína: Arnoux, à falência; Fréderic, a uma vida passiva, que não decola. Denuncia-se, então, a incompatibilidade entre os dois universos e o equívoco da "existência dupla", do "quiproquó do vaivém, espontâneo, provocado ou explorado". Assinala-se o "choque de possíveis estruturalmente inconciliáveis" (BOURDIEU, 1996, p.34).

No prólogo "Flaubert analista de Flaubert", Bourdieu empreende uma análise sociológica a partir de uma leitura interna da obra - isto é, da estrutura do espaço social no qual transcorrem as aventuras de Fréderic -, conduzida pelo conceito-metodológico de "campos sociais", caro ao sociólogo:

Flaubert instaura as condições de uma espécie de experimentação sociológica: cinco adolescentes - entre os quais o herói, Fréderic -, provisoriamente serão lançados nesse espaço, como partículas em um campo de forças, e suas trajetórias serão determinadas pela relação entre as forças do campo e sua inércia própria. (BOURDIEU, 1996, p . 24)

Ocorre que, de acordo com Bourdieu, esta é a mesma estrutura social na qual o próprio Flaubert está situado. Assim, faz-se possível estabelecer a relação entre o criador, a obra e o campo social no qual estão inseridos e entender as relações de força que se estabelecem entre essas instâncias, especificamente, o surgimento de um campo artístico autônomo na França no século XIX e a posição de Flaubert nesse contexto.

Daí a relação tantas vezes evocada entre Flaubert e Frédéric, tanto no que se aproximam quanto no que se distanciam. Autor e personagem se assemelham por uma adolescência romanesca dos que levam a ficção a sério porque não conseguem levar a sério o real - alodoxia ou bovarismo: erro de 
percepção e de apreciação que consiste em reconhecer uma coisa por outra. Ou, mais detalhadamente: "pendor de certos espíritos românticos para emprestarem a si mesmos uma personalidade fictícia e a desempenharem um papel que não se coaduna com a sua própria natureza" (MARIA CARPEAUX; FLAUBERT, 2011, p. 7). Lembram, portanto, que a "'realidade' pela qual medimos todas as ficções não é mais que o referente universalmente garantido de uma ilusão coletiva" (BOURDIEU, 1996, p. 27). Tal como para Dom Quixote: ou todas as histórias são verdadeiras, ou todas as histórias são falsas. De fato, conta-se que Flaubert admitia que as origens de Bovary estavam em Dom Quixote, autor que admirava declaradamente. Os dois protagonistas são leitores ávidos da literatura popular da sua época e conduzem suas vidas segundo um desejo de imitar a ficção, conduta que acabou levando herói e heroína à destruição, frustração e, por fim, à morte. E não são poucas as personagens literárias que sofrem desta patologia, funcionando como uma espécie de crítica da ficção e da limitação da artificialidade. Diz-se "bovarismo" assim como se diz "quixotismo", "hamletismo", "donjuanismo".

O triste fim de Emma Bovary é creditado em grande parte a um consumo excessivo de novelas românticas, que levou a protagonista a viver entre a realidade da vida provinciana francesa e as ilusões da narrativa romântica trivial. Sabemos que Flaubert foi ele mesmo um ávido leitor de novelas românticas durante sua época de estudante no Collège de Rouen, mas que eventualmente se tornou precursor de uma estética de repúdio total ao que Emma Bovary adorava ler. Muitos estudos empenharam-se em mostrar o que Flaubert tinha em comum com Emma Bovary, principalmente com o "objetivo de provar como ele transcendeu esteticamente o dilema no qual ela soçobrou na "vida real"” (HUYSSEN, 1997, p. 42). Esta história é frequentemente revisitada por críticos em alusão a uma das vozes centrais do modernismo; podemos encontrá-la no capítulo "A cultura de massa enquanto mulher”, do livro Memórias do modernismo, de Andreas Huyssen.

Bourdieu afirma: “o ideal da percepção 'pura' da obra de arte, enquanto obra de arte, é o produto da explicitação e da sistematização dos princípios da legitimidade propriamente artística que acompanham a constituição de um campo artístico relativamente autônomo" (BOURDIEU, 2006, p. 33). O que definiria a linha da fronteira, sempre incerta e historicamente mutável, entre o mundo dos objetos técnicos e o mundo dos objetos estéticos, que legitima a obra de arte, seria a "intenção": disposição inteiramente estética - e não ética - que afirma o primado do modo de representação sobre o objeto da representação. Embora seja praticamente impossível determinar cientificamente o momento em que um objeto trabalhado se torna uma obra de arte, como afirma Panofsky, citado por Bourdieu, este momento seria aquele em que a forma prevalece em relação à função.

Trata-se, portanto, de passar de uma arte que imita a natureza para uma arte que imita a arte, numa ruptura com a atitude habitual diante da obra de arte, que se baseava nos esquemas do ethos que são válidos para as circunstâncias da vida. Esta seria uma disposição popular que anexaria a "estética à ética" que levasse a acreditar "ingenuamente" nas coisas representadas, ao passo que a disposição intelectual tenderia a acreditar na representação, a partir de um ethos de distanciamento eletivo.

Essa autorreferencialidade, por sua vez, faz um apelo ao olhar histórico que permitisse identificar o traço distintivo, a propriedade estilística das obras de arte, numa espécie de competência cultural específica. Portanto, esse "olhar" seria um produto da história reproduzido pela educação. Essa ideia Bourdieu apresentou na introdução de $A$ distinção, em que desenvolve a tese de que os gostos funcionam como marcadores privilegiados da "classe" e que "à hierarquia socialmente reconhecida das artes - e, no interior de cada uma delas -, dos gêneros, escolas ou épocas, corresponde a hierarquia social dos consumidores" (BOURDIEU, 2006, p. 9). Contra a ideologia segundo a qual os gostos são considerados um "dom da natureza", ele pretendeu demonstrar que as práticas culturais estão estreitamente associadas, em primeiro lugar, ao nível de instrução e, em segundo, à origem social.

Instaura-se, assim, um circuito de "produtores-para-produtores", ou de "produção restrita", nos termos de Bourdieu, numa circularidade entre produção e consumo, cuja lei fundamental é, em 
princípio, a independência em relação às solicitações externas: "exclui a busca do lucro e não garante nenhuma espécie de correspondência entre os investimentos e os rendimentos monetários; condena a procura das honras e das grandezas temporais." (BOURDIEU, 1996, p. 246). Contra a ideologia burguesa de consumo das massas, é preciso escrever para não ser lido, ou ser lido apenas por outros artistas; sendo assim, "a legitimidade da escrita passa a ser definida pelos pares, ou seja, por aqueles que escolhem a atividade literária como ocupação.” (ORTIZ, 1988, p.21).

Em contraposição, a "produção ampla", diretamente subordinada à satisfação das expectativas do grande público, regida pelo princípio de hierarquização externa, segundo o critério do êxito temporal medido com índices de sucesso comercial (por exemplo, tiragem do livro) ou de notoriedade social (condecorações, prêmios). Estabelecem-se, desse modo, dois princípios de diferenciação independentes e hierarquizados, adequados à natureza dos bens simbólicos, "realidades de dupla face".

Arte desinteressada: aquela que conhece lucros apenas simbólicos, ignorando sua faceta mercantil comprometida, como lucro econômico denegado. Portanto, o jogo da arte é, do ponto de vista dos negócios, um jogo de "quem perde ganha". O sucesso comercial pode ser contraproducente, pelo menos se ocorre a curto prazo, ao provocar perda de credibilidade e suspeita de vulgaridade e inferioridade intelectual em determinados círculos. Efeito que advém da sacralidade que se atribui à obra de arte pura, sem correspondente mundano e muito menos monetário, de um comércio das coisas para as quais não há comércio, que não se vende nem é feito para ser vendido:

Nesse mundo econômico invertido, não se pode conquistar o dinheiro, as honras (era bem Flaubert que dizia: 'As honras desonram'), as mulheres, legítimas ou ilegítimas, em suma, todos os símbolos do sucesso mundano, sucesso no mundo e sucesso neste mundo, sem comprometer sua salvação no outro. (BOURDIEU, 1996, p. 37)

Logo, neste novo regime estético, a figura do "artista maldito" - sacrificado neste mundo e consagrado no outro - ganha contornos de vítima provisória e herói avesso a louvores e a retribuições. A rejeição é favorável diante dos erros de julgamento e de apreciação dos críticos e públicos do passado. Desconfia-se da fama terrena em privilégio da garantia de um lugar no panteão dos grandes artistas, este seleto grupo canônico - constituído, em sua maioria, por personalidades que já repousam a sete palmos -, redenção para os sacrifícios desta vida.

Ferrenho defensor da "arte pela arte", Flaubert tenciona demarcar o campo literário separado dos demais e eximi-lo de qualquer comprometimento, conveniência ou concessão do mercado aos salões, dos prêmios à Academia, da massa e dos poderosos. Uma arte que tende a recusar não somente os "programas" impostos a priori, como também as interpretações acrescentadas a posteriori. Insiste na autonomia da arte, sua radical separação da cultura do cotidiano, seu desinteresse e distância em relação a assuntos políticos e sociais. Porém, é sobretudo em oposição à incipiente classe burguesa os novos mestres da economia - no controle da produção cultural do século XIX, principalmente por intermédio da imprensa, que Flaubert e Baudelaire, entre outros, se levantam.

Como antídoto a esta nova conformação, os escritores modernos, com Flaubert e Baudelaire à frente, empreendem uma ruptura tanto em relação à ideologia religiosa, quanto em relação à ideologia aristocrática ou burguesa, colocando-se como independentes de qualquer tipo de ideologia, protegidos pelo campo específico da literatura. Estabelecido este campo, empreende-se uma "volta reflexiva e crítica dos produtores sobre sua própria produção" (BOURDIEU, 1996, p. 334), seus princípios e pressupostos específicos, reflexão que privilegia a maneira, a forma, o estilo, a arte em detrimento do assunto, sob o argumento de que a forma revela o caráter insubstituível do produtor e do produto portanto, sua especialidade - enquanto o conteúdo seria mais suscetível aos precedentes da demanda. De acordo com Bourdieu: 
Afirmar a autonomia da produção é conferir o primado àquilo de que o artista é senhor, ou seja, à forma, a maneira e o estilo, em relação ao 'indivíduo', referente exterior, por onde se introduz a subordinação a funções - ainda que se tratasse da mais elementar, ou seja, a de representar, significar e dizer algo (BOURDIEU, 2006, p. 11).

Virginia Woolf, conta-nos Bourdieu em uma passagem de A distinção, era uma crítica ferrenha dos romances de H.G. Wells, de Johnn Galsworthy e de Arnold Benett. O motivo era deixarem um sentimento estranho de incompletude e de insatisfação e suscitarem o sentimento de que é indispensável "fazer algo, inscrever-se em uma associação ou, ainda de modo mais desesperado, assinar um cheque" (BOURDIEU, 2006, p.38). Uma obra como Orgulho e preconceito, por sua vez, perfeitamente autossuficiente, inspiraria apenas o desejo de ser relida e melhor compreendida. Contra todas as ideologias, surge a "ideologia da textualidade".

Um dos exemplos desta estética seria a famosa impassibilité de Flaubert, e seu desejo de escrever um livro sobre nada, um livro sem laços externos, que se manteria coeso pela força interna de seu estilo. Desse predicado resultaria seu "aspecto abstrato de pura negatividade" (ORTIZ, 1988, p. 20). Sobre isso professou Zola a respeito de Flaubert: "É o negador mais amplo que tenhamos tido em nossa literatura. Professa o verdadeiro niilismo —uma palavra em ismo que o teria posto fora de si - nunca escreveu uma página onde não tenha cavado nosso nada" (ZOLA apud BOURDIEU, 1996, p. 114).

Tem-se aí a tonalidade flaubertiana marcada pelo refinamento da escrita e trivialidade extrema do assunto. A respeito de Madame Bovary, encontramos comentários sobre o desperdício de tanta estilística para uma história tão "vulgar". No entanto, segundo Bourdieu, é justamente a capacidade de transmutar o aspecto mais comum da vida em experiência estética "pura", do primado da forma sobre a função, o caráter concessor de "distinção", numa "completa inversão da disposição popular que anexa a estética à ética” (BOURDIEU, 2006, p. 11). Expressão que resume seu programa estético: "escrever bem o medíocre", numa espécie de democracia [em relação ao tema] nas letras.

No âmbito das artes plásticas, foi Manet, com seu Almoço na relva, e a "instituição antiinstitucional" do Salon des Refuses, que liderou a ruptura com a arte "oficial", do Salon de Paris. Emerge daí o movimento impressionista para o qual tudo é assunto, a diferença está nas impressões. "Manet e todos os impressionistas depois dele repudiam qualquer obrigação, não apenas de servir, mas também de dizer alguma coisa" (BOURDIEU, 1996, p.158), em uma valorização da representação sobre o que é representado, uma supremacia dos aspectos formais da obra. Desde Manet, a pintura é uma persistente elaboração do próprio meio: "a planura da tela, a estruturação da notação, da pintura e da pincelada, a questão do quadro" (HUYSSEN, 1997, p.54). Espécie, portanto, de democracia temática nas artes.

Embora defensor de uma "estética livre" e da irrelevância em relação ao tema, Zola, cujos romances alcançaram comprometedoras tiragens e que se aproximou do modernismo a partir do olhar clínico e dissecador do naturalismo, apresenta um contraponto da relação entre arte e dinheiro e lembra que foi o dinheiro que libertou o escritor da dependência dos mecenas aristocráticos e dos poderes públicos: "É preciso aceitá-lo sem remorso nem infantilidade, é preciso reconhecer a dignidade, o poder e a justiça do dinheiro, é preciso abandonar-se ao espírito novo.” (ZOLA apud BOURDIEU, 1996, p. 112).

Esta"economia invertida" confere todo o seu peso às propriedades herdadas, condição de sobrevivência na ausência de um mercado possível. Outra conclusão a que Flaubert chega é que, se o autor quer ganhar dinheiro com sua pena, é preciso fazer jornalismo, folhetim ou teatro.

$\mathrm{O}$ pensamento de Flaubert ressoa sobre a hierarquia dos gêneros que se configurou com a autonomização do campo literário e a ascensão do mercado de bens culturais. O critério de julgamento dos pares literários encontrava-se em razão inversa ao sucesso comercial obtido, à diferença do que 
se observava no século XVII, "no qual as hierarquias eram mais ou menos confundidas, sendo os mais consagrados entre os homens de letras, especialmente os poetas e os eruditos, os mais bem providos de pensões e de benefícios” (BOURDIEU, 1996, p. 113/114). De acordo com a lógica própria do campo literário, os gêneros distinguem-se segundo a aceitação do público e o potencial lucro comercial (teatro, romance, poesia), o prestígio no interior do campo e o menosprezo à demanda externa (poesia, romance, teatro). Intensifica-se, dessa forma, a estrutura dualista, em que o crédito simbólico tende a variar em proporção inversa ao lucro econômico.

Devidamente amaldiçoado pelo campo literário restrito e, na mesma proporção, aclamado pelo público amplo, o folhetim, considerado uma forma menor de ficção em prosa, funciona como exemplo clássico da separação entre os polos de produção cultural. Foi, de fato, por meio dos jornais, e mais especificamente dos folhetins, dos quais estão invariavelmente dotados, que o "industrialismo penetrou na literatura após ter transformado a imprensa" (BOURDIEU, 1996, p.70). Apelidado de "filé mignon do jornal", dada a capacidade de atrair leitores e alavancar as vendas, o romance publicado em capítulos no pé da primeira página de um periódico com uma finalidade precisa - o entretenimento - foi o modelo exemplar e o propulsor da literatura industrial.

Marlyse Meyer, na extensa pesquisa que resultou no livro Folhetim, comenta: “A publicação do folhetim parece imprescindível à vida do jornal. Não faltam indícios da correlação entre a prosperidade do jornal e o folhetim" (MEYER, 1996, p. 297). Afirma-se a força da ficção sobre a força do fato jornalístico, uma vez que o folhetim passou a conferir status ao jornal, e não o contrário. Na França, onde foi concebido, e cujo auge aconteceu na década de 1840, servia como "chamariz aos leitores afugentados pela modorra cinza a que obrigava a forte censura napoleônica” (MEYER, 1996, p. 54). A partir de então, "não se trata mais, para o romance-folhetim, de trazer ao jornal o prestígio da ficção em troca da força de penetração deste, mas pelo contrário, é o romance que vai devorar seu veículo" (MEYER, 1996, p. 60).

Praticamente toda prosa saía nesse formato e, se obtivesse sucesso, era posteriormente lançada em volumes, também bastante disputados - o negócio do jornal era, portanto, estendido ao negócio dos livros. Além disso, os melhores folhetinistas eram disputados a peso de ouro, avançando um estágio na profissionalização do escritor, tornado persona literária e cativo de um público ao qual presta contas. Entretanto, agradava o público na mesma medida em que desagradava a crítica: "Estes decretam, mas aqueles sustentam. Os romances não se escrevem para a crítica, escrevem-se para o público, para o grosso público, que é o que paga" (MEYER, 1996, p. 307). Isso não impediu, porém, que se misturasse um "mau gênero" com "bons autores", unindo qualidade e interesse comercial. No Brasil, é um modo de publicação que será também o de Alencar, Macedo, Machado, sem que entretanto tais romances sejam forçosamente romances-folhetim: "No entanto, é evidente que tal modo de publicação, com suas exigências próprias de cortes de capítulo, de fragmentos que todavia não destruam a impressão de totalidade e continuidade, haveria de influenciar todo romance a partir de então" (MEYER, 1996, p. 63).

Sucesso de fórmula, com a estratégia de deixar em suspenso o capítulo seguinte para prender a atenção do leitor e fazê-lo comparecer às bancas diariamente ou manter a assinatura, o "romance picadinho" inevitavelmente deixou marcas na fatura do texto, instituindo o gancho entre os capítulos e na adoção de uma linguagem cotidiana mais próxima do leitor - que tendiam a se manter quando as narrativas ficcionais eram transformadas em livros. Meyer resume as características técnicas e afetivas do gênero:

Comum a todos, e importantíssimo, era o suspense e o coração na mão, um lencinho não muito longe, o ritmo ágil que sustentasse uma leitura ainda às vezes soletrante, e a adequada utilização dos macetes diversos que amarrassem o público e garantissem sua fidelidade ao jornal, ao fascículo e, finalmente, o levasse ao livro. (MEYER, 1996, p. 303) 
Em Narrativas Migrantes, Vera Follain de Figueiredo discorre a respeito das transformações resultantes desse processo, ao pôr em relevo a possibilidade aberta pela imprensa de se "ultrapassar as distinções convencionais entre gêneros, entre ensaístas e ficcionistas e, principalmente, entre autores e leitores":

Com os jornais, teria surgido um novo tipo de leitor - o leitor moderno - e com ele, um novo tipo de escrita, decorrente da circulação acelerada dos textos a da propagação da leitura extensiva. Os autores procurariam atender à demanda desse tipo de leitor extensivo que consome diversos e numerosos impressos, o que alteraria o estilo, a maneira de escrever: os textos tenderiam a se aproximar da escrita comum, propiciando a superação das esferas compartimentalizadas de competência, ou seja, a diluição das fronteiras entre autores e público.(FIGUEIREDO, 2010, p. 13)

São várias as causas que impulsionam o consumo da leitura na Europa em fins do século XIX, difundindo-a entre a população: "advento de uma nova tecnologia que pode baratear a produção, facilidade de circulação com a expansão das vias de comunicação (particularmente a via férrea), melhoria do nível de vida da população, acesso generalizado à escola".(ORTIZ, 1988, p. 24) Misturada à questão da popularização da leitura - embora a atribuição do termo "popular" em uma sociedade na qual a cultura letrada ainda estava restrita a uma classe dominante seja um tópico controverso, mesmo na Europa para não falar no Brasil - está a questão do gênero do leitor.

Quem lia o folhetim e os romances? Quem era seu destinatário? Quem lê romances é, principalmente, a mulher, e os moralistas condenam a leitura desses livros, por considerarem-nos imorais ou perigosos, uma vez que apelam para o feitiço da imaginação. No já citado capítulo "A cultura de massa enquanto mulher", Huyssen apresenta alguns aspectos sobre as inscrições de gênero no debate a respeito da cultura de massa. Enquanto a mulher - Bovary - é apresentada como uma leitora de literatura inferior - subjetiva, emocional e passiva -, o homem - Flaubert - se apresenta como um escritor da literatura genuína e autêntica - objetivo, irônico, e com o controle de suas formas estéticas. A ideia de uma feminilidade que a tudo envolve ameaça as fronteiras estritas e estáveis e desestabiliza o projeto modernista de um campo demarcado. Está associada à cultura de massa, como a tentação do consumo.

Se a análise de Bourdieu situava o modernismo sobretudo em oposição à emergente e exploradora cultura burguesa, Huyssen afirma que é preciso considerar outro fenômeno da época: "a cultura vernacular e popular, que se transformou cada vez mais na moderna cultura de massa comercial" (HUYSSEN, 1997, p.10). É importante pontuar, no entanto, que por cultura de massa entende-se "folhetins, seriados, revistas populares e para a família, todo o material dos clubes de livros, os bestsellers de ficção e coisas semelhantes, mas não a cultura da classe trabalhadora ou formas residuais de culturas populares ou folclóricas mais antigas" (HUYSSEN, 1997, p. 48).

O termo impreciso possibilita equívoco e indeterminação em relação a quem produz e a quem consome tal cultura, como se desse margem à interpretação de que se trata de uma cultura brotada espontaneamente das massas, uma forma contemporânea de "arte popular". No entanto, embora tenha sido substituído em alguns casos por indústria cultural, termo cunhado por Adorno e Horkheimer, para especificar um sistema de produção que é feito para a massa e não propriamente pela massa, é pontual ao dar a ideia de produção e consumo massificado, homogêneo, em franca oposição à distinção dos campos especializados. A mudança de terminologia, porém, tem uma intenção clara: "sugerir que a cultura de massa moderna é administrada e imposta de cima para baixo e que a ameaça que ela representa reside não nas massas, mas naqueles que comandam a indústria" (HUYSSEN, 1997, p. 46).

É justamente em termos de uma "ansiedade" contra a contaminação por seu "outro" - "uma cultura de massa cada vez mais consumista e envolvente" (HUYSSEN, 1997, p. 7) - que Huyssen aborda o projeto modernista e sua estratégia consciente de exclusão. Não é apenas a partir da ascensão de 
uma alta arte que define seu programa, porém, na constituição de uma cultura de oposição, que tem na relação com a cultura de massa seu subtexto. Esta se estabelece como o "outro" do modernismo, o espectro que o assombra e o ameaça. E é somente fortalecendo suas fronteiras que pode manter sua posição de adversária da cultura do cotidiano burguês, tanto quanto da cultura de massa e do entretenimento, que são vistos como as formas principais da articulação cultural burguesa.

"Desviar-se de alguma coisa, proteger-se de alguma coisa" (HUYSSEN, 1997, p. 44) - gestos fundamentais da nova estética. De fato, o projeto modernista, ao menos em seu registro básico, parece se afirmar em grande parte por uma postura reativa. A autonomia da obra de arte modernista é quase sempre o resultado de uma resistência, uma abstenção e uma supressão: "resistência à tentação sedutora da cultura de massa, abstenção do prazer de tentar agradar a um público mais amplo, e supressão de tudo o que pudesse ser ameaçador para as demandas rigorosas de ser moderno e à frente de seu tempo" (HUYSSEN, 1997, p. 55).

Esse é o relato clássico do modernismo canônico dos movimentos que propunham a radical autonomização do campo da arte e a demonização da "baixa" cultura, que teve sua expressão mais marcante na virada do século XIX e novamente no período após a Segunda Guerra Mundial com a canonização do "alto modernismo". Mas é preciso ter em conta que a essa noção universalizante somam-se outros níveis de modernismo que desestabilizavam a conservadora divisão da cultura e a severa restrição do campo da arte, permitindo-se uma abertura em relação à cultura de massa e às formas populares de expressão. Uma figura emblemática desse processo é Brecht e o teatro do oprimido, seu mergulho em direção à cultura vernacular e à politização da arte, o projeto de criar uma cultura de vanguarda para a emancipação das massas, numa "pedagogia revolucionária" (ECO, 1991, p. 50). A técnica dramática do "efeito de estranhamento", com seu poder de distanciamento e desmistificação, herdava e transformava os precedentes da crítica ideológica do Iluminismo, na intenção de usá-los contra a hegemonia cultural burguesa, na construção de uma cultura socialista de massa.

Uma espécie de "revolta contra certos aspectos do moderno" e um desafio a um "impulso para a frente" foram propostos pela vanguarda histórica, cujo principal substrato que retemos aqui é sua intenção de preencher a lacuna entre arte e vida - que havia sido tão profundamente marcada pelo modernismo - numa unidade artística e política. Na tentativa de "tapar esse buraco", era preciso destruir a chamada "arte-instituição", termo que se refere ao panorama institucional no qual a arte era produzida, distribuída e recebida na sociedade burguesa. No capítulo "A dialética oculta - vanguardatecnologia - cultura de massa", Huyssen pretende resgatar o sentido original, iconoclasta e subversivo da vanguarda histórica como contraponto à sua canonização como empreendimento de elite, acima do político e do cotidiano, pelo alto modernismo, e enfatizar a relação alternativa que pretendeu estabelecer entre a "alta" e "baixa" cultura.

Para desenvolver sua análise, Huyssen parte dos estudos do teórico da vanguarda Peter Bürger, que aponta como grande meta dos movimentos artísticos como o Dadá, o surrealismo e a vanguarda russa pós-1917 a reintegração da arte na práxis da vida e a rebelião ativa que faria da arte propulsora de uma mudança social. Embora tenham sido tão diferentes entre si, tais movimentos compartilhavam um imaginário: pregava-se a libertação da "arte qua arte" e da "arte-instituição". Brecht argumentava que o caráter revolucionário da vanguarda devia ser julgado de acordo com sua relação com os poderes institucionais, e que a real revolução na arte significaria uma transferência dos meios de produção: "a verdadeira pergunta é quem é o dono dos teatros, das editoras e dos meios de comunicação. (SARLO; MARQUES \& VILELA, 2002, p.47)"

Portanto, o sucesso do projeto vanguardista pressupunha uma transformação na estrutura da sociedade burguesa, a partir da afinidade entre arte e revolução. Seu caráter utópico visava o futuro, na percepção de que a arte persegue um télos que levasse ao progresso. Existia, por conseguinte, uma 
carga de responsabilidade assumida pela vanguarda de "mudar a vida, mudar a sociedade, mudar o mundo" (HUYSSEN; HOLANDA, 2002, p. 49). A conclusão é que, como essa transformação não ocorreu, a própria vanguarda enquanto movimento tinha de fracassar.

Hoje, sabemos, a vanguarda e a crença no poder da arte de mudar o mundo é um projeto obsoleto e raramente evocado como empresa viável. A insistência da vanguarda na revolta cultural se chocava com a necessidade burguesa de legitimação cultural, e o desdobramento desse embate resultou na falência da primeira e na permanência da dominação da segunda. A ascensão da indústria cultural no século XX é apontada como motivadora do declínio da vanguarda histórica, uma vez que o tipo de vida que ela suscitou vai de encontro ao programa vanguardista de utopia e libertação. Ironicamente, foi a tecnologia - que propiciou à vanguarda, na fabricação do objeto artístico, sua ruptura radical com a tradição - que pavimentou a estrada da consolidação da indústria cultural e, consequentemente, dos novos modos de vida. No fim das contas, apesar do caráter revolucionário da vanguarda, foi a indústria cultural, e não a vanguarda, que conseguiu transformar o cotidiano no século XX (HUYSSEN, 1997, p.29).

A força da cultura afirmativa do capitalismo, intensificada na metade do século XX, absorveu as invenções artísticas e demais manifestações da vanguarda, e a proposta de "estetização da vida" culminou na estetização dos produtos e mecanismos que alimentam sua engrenagem, "de filmes de Hollywood, televisão, design industrial e arquitetura até a estetização da tecnologia e a estética da mercadoria" (HUYSSEN, 1997, p.37).

Portanto, qualquer projeto de tentar reviver ou resgatar a vanguarda histórica hoje é tido como anacrônico. Entretanto, afora sua marca utópica, a relação alternativa que as correntes vanguardistas pretenderam estabelecer com a cultura de massa, colocando abaixo as barreiras que haviam sido construídas pela modernidade e aproximando a arte da vida, especialmente via novas tecnologias, caminham em paralelo e ajudam a compreender o traço integrador próprio da indústria cultural e, ao cabo, da pós-modernidade. Porque, tal como a vanguarda histórica, embora de formas diferentes, o pós-modernismo rejeita as teorias e práticas do "Grande Divisor", rompendo, sobretudo, com a dicotomia entre "alta" e "baixa" cultura e intensificando o trânsito entre as esferas culturais.

Vera Follain de Figueiredo aponta para a "necessidade de outros recortes, transversais às polarizações modernas, que permitam dar conta, por exemplo, da tenuidade das fronteiras entre a chamada alta cultura e cultura midiática de mercado" (FIGUEIREDO, 2010, p.11). Nas palavras de Huyssen, no ensaio "Literatura e cultura no contexto global" (HUYSSEN; MARQUES \& VILELA, 2002, p.33): “O que costumava ser uma divisão vertical se tornou, nas últimas décadas, uma zona fronteiriça horizontal de trocas e pilhagens, de viagens transnacionais de idas e vindas e todos os tipos de intervenções híbridas."

Mas, enquanto as vanguardas históricas organizavam seu movimento segundo a utopia do progresso e da emancipação das massas, o motor pós-moderno que impulsiona seu programa de uma cultura que integrasse o erudito e o popular é outro - o mercado de consumo. É esse o elo que liga as duas facetas do produto cultural - seu viés econômico e simbólico, mercadoria e significação -, ora pendendo para um lado, ora pendendo para o outro, em uma estética da negociação que visa satisfazer o gosto do público médio. Vera Follain de Figueiredo fala do declínio da "estética da provocação" entre os autores contemporâneos, visando alcançar o difícil equilíbrio entre agradar o público, obtendo sucesso comercial, e preservar a complexidade da obra, permitindo, por sua vez, diferentes níveis de leituras e atendendo um público variado. Segundo ela, "preserva-se o enredo, sem preconceito para com aquele leitor que visa divertir-se com a intriga. Por outro lado, oferece-se algo além da intriga, uma dimensão metalinguística e reflexiva, reforçada por inúmeras citações”. (FIGUEIREDO, 2010, p.61). 
Mais frequentemente, porém, assistimos à hegemonia da lógica "econômica" das indústrias culturais, que fazem do comércio dos bens simbólicos um comércio - quase - como os outros, dando prioridade ao lucro imediato e contentando-se em ajustar-se à demanda pré-existente da clientela. Renato Ortiz utiliza uma expressão de Foucault para sua definição: “eu diria que a indústria cultural age como uma instituição disciplinadora enrijecendo a cultura". (ORTIZ, 1988, p. 48). Como indicou Huyssen:

Hibridizações de todos os tipos acontecem agora, cada vez mais sob o signo do mercado. Mas mercados, mesmo mercados de nicho de elite, tendem a domesticar e igualar as arestas brutas e inovadoras da produção cultural. Elas preferem a fórmula de sucesso em vez de encorajar o ainda desconhecido, a experimentação e modos incomuns de expressão estética. (HUYSSEN; MARQUES \& VILELA, 2002, p.33).

Robert Stam, em O espetáculo interrompido, faz uma análise do filme O desprezo (1963), de Godard. O filme é uma crítica sobre o papel conflituoso do artista na sociedade do capital. Em cena, o próprio diretor Fritz Lang como o diretor Rheingold, sujeito aos caprichos e ao controle financeiro do produtor, na personagem de Prokosch. Em determinado momento do filme, o famoso diktat de Goebbels ("Sempre que ouço a palavra cultura, saco meu revólver") é enunciado por Prokosch, com alguma variação: "Sempre que ouço a palavra cultura, saco meu talão de cheque". Para o produtor, a arte é um artigo de consumo; e o artista, consequentemente, um comerciante do seu talento. O fascismo de Goebbels assassina literalmente a cultura; o capitalismo de Prokosch a assassina figurativamente. Além disso, o filme gira em torno do desvelamento das mediações discursivas, na defesa de uma arte autorreflexiva e em ataque à ilusão da transparência narrativa, própria ao cinema Hollywoodiano. $\mathbf{O}$ desprezo coloca em evidência a instância enunciadora por detrás da câmera, geralmente ocultada nas narrativas audiovisuais e, portanto, ausente da consciência do telespectador, abalando a ilusão da objetividade da imagem.

Além disso, apesar da flexibilização dos campos externa e internamente, a hierarquia dos gêneros prevalece em alguma medida no mercado de bens culturais. Os bens que se encontram no nível mais alto hierarquicamente são os menos passíveis de serem abertamente apropriados pela lógica mercadológica, e os que estão no patamar mais baixo, os mais suscetíveis de entrarem na engrenagem que rege o mercado, que tem na publicidade e no marketing suas ferramentas mais poderosas.

Por sua vez, Sérgio Sá, em A Reinvenção do escritor, livro em que analisa a figura do personagemescritor na literatura contemporânea, inserida no contexto da presença avassaladora dos meios de comunicação de massa, defende:

Esses estilos mediáticos têm sido, em alguns momentos, positivos para a literatura brasileira contemporânea. Ela saiu da torre do castelo, se interessou pelo mercado e pelo leitor, deixou um pouco de lado a vontade de ser genial, percebeu que, se não fizesse isso seria completamente engolida. Prestou atenção às exigências desse novo leitor-espectador. Por isso, esteve presente na mídia (SÁ, 2010, p.16).

Mas, afinal, o panorama apresentado aqui se aplica ao contexto brasileiro? Há sentido em se falar, no Brasil, da formação de um campo artístico autônomo no século XIX e de uma indústria cultural integradora das massas no século XX? Grande parte da análise deste artigo repousa sobre a sociedade europeia e as diferentes concepções do objeto artístico ao longo de um percurso que culminou com sua apropriação pelo mercado de bens simbólicos e do entretenimento. O Brasil, no entanto, não compartilha das mesmas etapas, não está em sincronia nem em sintonia com o processo histórico do "continente antigo". Aqui, a modernidade e os modernistas, na ausência de uma indústria cultural de traço integrador, concentraram-se na discussão sobre a nação, uma identidade ainda a ser construída. E nesses nem tão "tristes trópicos" as contradições de uma cultura artística e outra de mercado não se manifestam de forma antagônica. Vejamos a análise de Renato Ortiz sobre o tema: 
Se compararmos o quadro cultural brasileiro com o europeu, observamos que não se justifica uma nítida diferenciação entre um polo de produção restrita e outro de produção ampliada. As razões sociológicas para que isso aconteça são fortes. Devido à fragilidade do capitalismo existente, Florestan Fernandes o qualifica de "difícil", uma dimensão do mercado de bens simbólicos não consegue se expressar plenamente. Isso significa uma fraca divisão do trabalho intelectual e uma confusão de fronteiras entre as diversas áreas culturais. (ORTIZ, 1988, P.25/26).

Em um contexto de mercado consumidor incipiente, alto índice de analfabetismo, baixa escolarização e atividades culturais reduzidas, vemos o campo das artes se definindo mais por sua sobreposição do que pela sua autonomia. Ortiz cita Nélson Werneck Sodré para falar da confusão entre jornalismo e literatura no início do século XX, ao ponto de os diários serem escritos em uma "linguagem" empolada, inadequada para a veiculação de notícias. No Brasil, a literatura se legitima e se difunde através da imprensa: Para o escritor, o jornal desempenhava funções econômicas e sociais importantes: "era fonte de renda e de prestígio. Devido ao caso no qual um órgão voltado para a produção de massa se transforma em instância consagradora da legitimidade da obra literária" (ORTIZ, 1988, p.28/29).

Vimos isso no caso do folhetim, em que não se hesitava misturar um "mau gênero" com "bons autores", entre eles, Machado, Alencar, Azevedo, Bilac. Além disso, como falar de uma "literatura popular" quando grande parte do "povo" estava excluída da cultura letrada? Marlyse Meyer ecoa essa indagação:

É verdade que, neste país formado pelos padrões da oralidade, onde, nos primórdios do folhetim, dominavam as famílias extensas e casas recheadas de serviçais e, mais tarde, as habitações populares coletivas, cortiços e vilas operárias, há de se levar em conta o efeito multiplicador de uma oitiva coletiva durante os serões. (MEYER, 1996, p. 379).

Além do folhetim, outra ponte entre a cultura oral e a cultura letrada, no Brasil, foi a canção popular, a partir das composições de alto nível transmitidas através de um meio de ampla penetração e fácil assimilação. Atualmente, fala-se do rap como uma ferramenta para disseminar a literatura entre jovens de camadas mais pobres ou jovens avessos à literatura. O rapper Ferréz, no filme Palavra (en)cantada, fala que o rap é a continuação da literatura de cordel e afirma: "Faço rap para falar de literatura". Lirinha, da extinta banda Cordel de Fogo Encantado, recita no palco um poema de Cabral e o público o acompanha, em meio à música. No depoimento de Tom Zé, o músico sobrepõe a cultura do ouvido à do olho. José Miguel Wisnik fala da música popular como um "remédio-veneno", ao mesmo tempo sintoma e perspectiva, sinal de nossa carência e "estratégia originalíssima" para contorná-la. Andreas Huyssen discorreu a respeito disso:

Devemos abordar o tópico da mídia (oral/aural, escrita, visual) em toda a sua complexidade histórica, técnica e teórica, ao invés de continuar a confiar numa noção moralizante de cultura de mídia como popular e seu outro literário erudito na maneira modernista tradicional (HUYSSEN; MARQUES \& VILELA, 2002, p.30).

Num contexto de predominância oral/aural, rebate-se a ideia de uma cultura de massa associada à leitura, por isso se diz que passamos dos meios orais direto para os meios audiovisuais. Pois é só a partir dos anos 1970 que uma indústria cultural, incluindo aí o mercado editorial, começa a se firmar, em consonância com uma estabilidade econômica, que, sabemos bem, enfrentou inúmeros percalços ao longo do caminho. E é justamente nessa fase, como aponta Ortiz, que se consolidam os grandes conglomerados que controlam os meios de comunicação e da cultura popular de massa. Atualmente, começamos a ver surgir estudos relativos ao campo da cultura diante de um cenário econômico favorável e da expansão da classe $\mathrm{C}$, uma conjuntura nova cujos reflexos são visíveis no intercâmbio das esferas culturais. 
A partir da segunda metade do século XX, a ideia de um campo artístico autônomo e independente, radicalmente demarcado, foi perdendo força. Ao contrário, as fronteiras são cada vez mais fluidas e circula-se livremente sem temer a contaminação do objeto artístico. Esses efeitos são amplamente sentidos na produção literária contemporânea. Em primeiro lugar, identificamos uma literatura que não almeja se posicionar em um dos polos da esfera cultural e que, de certa forma, se interessou pelo mercado e pelo leitor. Uma das consequências disso é a constante presença do autor na mídia, divulgando sua obra, frequentemente em um diálogo aberto e veloz com seu público - um fenômeno que indica também uma busca pela referencialidade na figura do escritor. Essa busca também pode ser confrontada com a crise representativa e a proposta de autonomia dos sistemas sígnicos do modernismo. Nessa mesma perspectiva, ocorre, no mercado editorial, uma emergência da literatura testemunhal, da não ficção e da biografia, gêneros que transitam entre a "realidade" e a "ficção" e que constantemente colocam em xeque tais conceitos.

Além de resistir às categorias modernistas do "Grande Divisor", a literatura contemporânea é também reticente no que diz respeito a um "conceito" fechado e específico de literatura, em função, sobretudo, da expansão por outros meios e suportes e do uso de diferentes linguagens. Entre a verticalidade e a horizontalidade, funda-se um novo lugar na transversalidade, acabando com a ideia de obra como unidade fechada. Na fatura do texto, podemos identificar uma busca pela concretude na esteira da materialidade tecnológica, traduzida em hipertextos e em uma linguagem que busca a simultaneidade e a platitude das imagens, como se quisesse oferecer ao leitor uma sequência de quadros. Além disso, técnicas do cinema, como o flashback, o corte, as elipses temporais e o ritmo acelerado são cada vez mais encontradas na produção contemporânea. Narrativas curtas constroem uma ponte entre a ficção e a crônica, que ganha eficiência no instantâneo de uma vida fragmentada, realizando tanto uma ruptura com a tradição do passado como com a crença utópica de um progresso futuro.

A modernidade tardia encontra-se em diálogo constante com o projeto moderno que pretendeu fundar um campo específico para as artes e cuja importância estética e política é sentida no pensamento e nas práticas culturais contemporâneas. Atualmente, deparamo-nos com um campo artístico, mais especificamente literário, que vem sentindo as mudanças decorrentes de um fenômeno que, não sendo novo, ganhou novos matizes: a hegemonia dos meios audiovisuais, que deslocam a literatura do lugar que ela ocupava no mundo das artes e no mercado de bens culturais. Seja como continuidade ou, mais frequentemente, seja como resistência à modernidade, fato é que a modernidade tardia parece despreocupada com qualquer território delimitado: em vez de fundação de um novo lugar, a violação permanente de fronteiras, a transgressão. 


\section{Referências}

BOURDIEU, Pierre. As regras da arte: gênese e estrutura do campo literário. Tradução de Maria Lucia Machado. São Paulo: Companhia das Letras, 1996.

BOURDIEU, Pierre . A distinção: crítica social e julgamento. Tradução de Daniela Kern Guilherme J.F. Teixeira. Porto Alegre: Editora Zouk, 2006.

ECO, Umberto. Obra aberta. Tradução de João Rodrigo Narciso Furtado. São Paulo: Perspectiva, 1991.

FIGUEIREDO, Vera Follain de. Narrativas migrantes: literatura, roteiro e cinema. Rio de Janeiro: Ed.PUC-Rio: 7 letras, 2010.

FLAUBERT, Gustave. Madame Bovary. Tradução de Mario Laranjeira. Rio de Janeiro: Nova Fronteira, 2011.

FLAUBERT, Gustave. A educação sentimental. Tradução de João Barreira. São Paulo: Martin Claret, 2006.

HOLANDA, Heloísa Buarque de (Org). Pós-modernismo e política. Rio de Janeiro: Rocco, 2002.

HUYSSEN, Andreas. Memórias do modernismo. Tradução de Patricia Farias. Rio de Janeiro: Editora UFRJ, 1997.

HUYSSEN, Andreas . Mapeando o pós-moderno, in: HOLANDA, Heloísa Buarque de (Org.). Pósmodernismo e política. Rio de Janeiro: Rocco, 2002.

HUYSSEN, Andreas . Literatura e cultura no contexto global. In: MARQUES, Reinaldo; VILELA, Lúcia Helena (Org.). Valores - arte, política, mercado. Tradução de Julio Jeha. Belo Horizonte: Editora UFMG, 2002.

MARIA CARPEAUX. Prefácio de Madame Bovary. In: FLAUBERT, Gustave. Madame Bovary. Rio de Janeiro: Nova Fronteira, 2011.

MARQUES, Reinaldo; VILELA, Lúcia Helena (Org.). Valores - arte, política, mercado. Belo Horizonte: Editora UFMG, 2002.

MEYER, MARLYSE. Folhetim: uma história. São Paulo: Companhia das Letras, 1996.

ORTIZ, Renato. A moderna tradição brasileira. São Paulo: Brasiliense, 1988.

SÁ, SÉRGIO. A reinvenção do escritor: literatura e mass media. Belo Horizonte: Editora UFMG, 2010.

SARLO, Beatriz. A literatura na esfera pública, in: MARQUES, Reinaldo \& VILELA, Lúcia Helena (orgs). Valores - arte, política, mercado. Belo Horizonte: Editora UFMG, 2002.

SOLBERG, Helena. (Dir.) Palavra (En)cantada. Brasil: Radiante Filmes (Distribuição), 2008.

STAM, Robert. O espetáculo interrompido: literatura e cinema de desmistificação. Tradução de José Eduardo Moretzsohn. São Paulo: Paz e Terra, 1981. 
